\title{
Pre-labour Rapture of Membrane at Term in Patients with an Unfavorable Cervix: Active verses Conservative Management
}

\author{
Rowshan Afrooz, ${ }^{1}$ Abul Kalam Md. Faruq, ${ }^{2}$ Mitheel-Ibna Islam ${ }^{3}$
}

\begin{abstract}
Objective: The present quasi-experimental (comparative clinical trial) study was conducted to compare the outcome of active versus conservative management in patients with prelabour rupture of membrane (PROM) at term with an unfavourable cervix.

Materials \& Methods: The study was carried out at Gynae \& Obstetrics Department, Bangabandhu Sheikh Mujib Medical University (BSMMU), Dhaka over a period of 12 months from July 2009 to June 2010. Women admitted in the Obstetrics \& Gynaecology Ward of BSMMU with pre-mature rupture of membrane (PROM) at term with unfavourable cervix was the study population. A total of 86 women with rupture of membranes at $>$ 37 weeks of gestation with a single foetus in a cephalic presentation, Bishop's score below 6, absence of active labour, no history of previous uterine surgery, no contraindication to vaginal delivery, a normal cardiotocogram and an adequate pelvis on clinical pelvimetry were included in the study and divided into two groups - study group (who received $25 \mu \mathrm{g}$ of misoprostol every 6 hours in the posterior fornix of the vagina to a maximum of 4 doses) and control (who received conservative treatment for 24 hours).

Result: The result shows that the study and control groups were almost identical in terms of age $(p=0.058)$, parity $(p=0.812), H / O$ past abortion $(p=0.366)$. Majority $(94.3 \%)$ of the patients in case group and $64.4 \%$ in control group took 24 or $<24$ hours to deliver their babies. The mean interval between PROM and uterine contraction and that between ROM and delivery were significantly less in the study group than those in the control group ( $p<0.001$ and $p<0.001$ respectively). About $63 \%$ of study group experienced significant uterine contractions after $1^{\text {st }}$ dose, $23.3 \%$ after $2^{\text {nd }}$ dose, $9.3 \%$ after $3^{\text {rd }}$ dose and $4.7 \%$ after $4^{\text {th }}$ dose of misoprostol, while none of the patients in control group experienced significant contraction during the same period $(p<0.001)$. Twenty two $(50.6 \%)$ of controls needed oxytocin for induction as opposed to none in the study group. The need for oxytocin during labour in study group were significantly less (37.2\%) than that in control $(80.5 \%)(p=0.024)$. The incidence of failed induction was even less in study group $(11.6 \%)$ than that in control $(44.2 \%)(p=0.001)$. Two $(4.7 \%)$ patients in the study group developed uterine hyperstimulation, $2.3 \%$ uterine tachysystole and another $2.3 \%$ nausea/vomiting while none of patients in control group developed the same complications. One $(2.3 \%)$ of the patients in study group experienced chorioamnionitis and $9.3 \%$ exhibited group-B streptococci in high vaginal swab culture. In contrast, $18.6 \%$ of the controls developed chorioamnionitis and $14 \%$ showed the presence of group-B streptococci in high vaginal swab. In terms of mode of delivery, normal vaginal delivery (NVD) occurred in $88.4 \%$ study group as compared to $53.5 \%$ of control group $(p<0.001)$. There was no significant difference between the groups in terms of foetal distress $(p=0.747)$ and neonatal sepsis $(p=0.121)$. Over half of the patients in the both groups had a history of less than 4 vaginal examinations during labour. There was no significant differences between the groups with respect to Apgar score at 1 minute of birth, neonatal sepsis and foetal distress $(p=0.063, p=0.121$ and $p=0.747$ respectively).

Conclusion: The study concluded that management of premature rupture of membrane with unfavourable cervix using vaginal misoprostol increases the rate of normal delivery thereby reducing the risk of caesarean section, while conservative management of premature rupture of membrane usually fails to augment normal delivery. So it is safer to give induction to women presenting with premature rupture of membrane with unfavourable cervix using vaginal misoprostol.
\end{abstract}

Key words: Induction of labour, active management, conservative management, prelabour rupture of membrane (PROM) at term and unfavourable cervix.

\footnotetext{
Authors' information:

${ }^{1}$ Dr. Rowshan Afrooz, MBBS, MS (Obstetrics and Gynaecology), Assistant Professor, Obstetrics and Gynaecology, North Bengal Medical College, Sirajgonj.

${ }^{2}$ Dr. Abul Kalam Md. Faruq, BDS, MS (Oral \& Maxillofacial Surgery), Assistant Professor, Oral \& Maxillofacial Surgery, Dhaka Dental College, Dhaka.

${ }^{3}$ Dr. Mitheel-Ibna Islam, MBBS, FCPS (Obstetrics and Gynaecology), DGO, Medical Officer, 250 Bed Shahid Shaikh Abu Naser Specialist Hospital, Khulna.
}

Correspondence : Dr. Rowshan Afrooz, Cell Phone: +88 01823883265, E-mail:dr.akmfaruq@yahoo.com 


\section{INTRODUCTION}

Pre-labour rupture of membrane (PROM) occurs in about $8 \%$ of pregnancies; ${ }^{1}$ about $80 \%$ of which are term pregnancies. ${ }^{2}$ If labour is not induced, over $60 \%$ of these pregnant women begins labour spontaneously within 24 hours and over 95\% within 72 hours. As the time between the rupture of the membranes and the onset of labour increases, so does increase the risk of maternal and foetal infection. For these reasons, many physicians recommend that labour be induced if the pregnancy is at term and labour does not begin spontaneously shortly after the membrane's rupture. Others believe that waiting for labour to begin spontaneously is preferable for mothers, if there is no evidence of foetal or maternal compromise. However, there is limited information about which approach is better. ${ }^{3}$ The most serious complications of PROM at term is maternal and neonatal infection and the risk of complication increases as the duration of PROM prolongs. ${ }^{3-5}$ Therefore, the goal of management of PROM at term is to deliver the infant as early as possible. The management of term pregnancy with PROM with unfavourable cervix remains controversial. Active induction of labor soon after PROM reduces the risks of maternal and foetal sepsis ${ }^{4}$ compared with conservative management, and is associated with a shorter interval from PROM to significant uterine contractions and delivery. ${ }^{6}$

For the labour that is induced, the timing of the induction is controversial. Indeed, the decision to induce labour often depends more on the convenience of the physicians, nurses or midwives than on the actual time that elapsed after rupture of the membranes. If labour is induced, the method of induction is usually by intravenous administration of oxytocin. More recently, prostaglandins, followed by an infusion of oxytocin, if necessary, have been used, though it is not widely established that the latter method is better. ${ }^{4}$ Misoprostol is a prostaglandin E1 analogue which is rapidly absorbed after oral administration. Its uterotonic and cervical ripening properties have become increasingly well-known, and the wealth of information has emerged from studies investigating its potential use in obstetrics
\& gynaecology. ${ }^{7}$ Misoprostol has been the drug of choice for induction of labor in developing countries, because it is cheap, stable at room temperatures, does not require refrigeration prior to use, is easy to prepare and the route of administration is convenient.8,9 In most trials, prostaglandins have been administered vaginally, which results in a longer half-life than oral misoprostol administration. However, low dosing may have an advantage in induction of labour because of the reduced risks of uterine hyperstimulation and tachysystole. ${ }^{10}$ The advantages of misoprostol with reference to PROM is the avoidance of repeated vaginal examination which subsequently reduces the risk of sepsis for both mother and baby. ${ }^{11}$ The recommended dose for vagianl misoprostol for labour induction is 25 $\mu \mathrm{gm}$ every six hours. ${ }^{12}$ There are two management options for PROM at term: treating the patient conservatively for 24 to 72 hours or active management using oxytocin or prostaglandins to accelerate cervical ripening and avoid chorioamnionitis, maternal and neonatal morbidity. ${ }^{13-14}$ The background information so far discussed shows that the efficacy and safety of misoprostol in case of PROM at term with unfavourable cervix is disputable. The objective of the present study was to compare the outcome of active versus conservative management of patients with prelabour rupture of membrane (PROM) at term with an unfavourable cervix.

\section{MATERIALS \& METHODS}

This quasi-experimental (comparative clinical trial) study was conducted over a period of 12 months from July 2009 to June 2010 in the Department of Obstetrics \& Gynaecology, BSMMU Hospital, Dhaka. Women admitted in the Obstetrics \& Gynaecology Ward of BSMMU with PROM at term with unfavourable cervix were study population. Pregnant women with ruptured membranes at > 37 weeks of gestation, a single foetus in cephalic presentation, Bishop's score below 6, absence of active labour, no history of previous uterine surgery, no contraindication to vaginal delivery, a normal cardiotocogram and an adequate pelvis on clinical pelvimetry were included in the study. A total of 86 such patients 
were enrolled in the study. For random allocation of patients into groups, there were 2 cards - one marked "A" and another "B". The doctor on duty shuffled the cards and patients who consented for participating in the study were asked to draw a card blindly. Patients who have had cards marked "A" were allocated into active management group (study group, $n=43$ ), while patients with cards marked " $B$ " were assigned to conservative management group (control group, $n=43$ ). Study group received $25 \mu \mathrm{g}$ of misoprostol every 6 hours in the posterior fornix of vaginal to a maximum of 4 doses. Control group received conservative treatment (rest in bed) for 24 hours. The primary outcome variable was mode of delivery (normal or caesarean) and secondary outcome variables were need of oxytocin for induction of labour and the complications developed. Data were processed and analysed using software SPSS (Statistical Package for Social Sciences) version 16.0. The statistics used to analyse the data were Chi-square $\left(\chi^{2}\right)$ and Student's t-Test. The level of significance was set at 0.05 and $p$-value was considered significant.

\section{RESULTS}

There was no significant difference between the groups in terms of age $(p=0.058)$, though patients of 30 or more than 30 years were higher in the study group compared to that in the control group. The subjects in both groups were predominantly primipara $(69.8 \%$ and $72.1 \%$ respectively) with no significant difference between the groups in terms of parity $(p=0.812)$ and past history of abortion ( $p=0.366$ ) (Table I). Majority $(94.3 \%)$ of the patients in study group and $64.4 \%$ in control group deliver their babies within 24 hours. The mean interval between ROM and uterine contraction and that between ROM and delivery were significantly less in the study group than those in control group $(p<0.001$ and $p<0.001$ respectively). About $63 \%$ of study group experienced significant uterine contractions after $1^{\text {st }}$ dose, $23.3 \%$ after $2^{\text {nd }}$ dose, $9.3 \%$ after $3^{\text {rd }}$ dose and $4.7 \%$ after $4^{\text {th }}$ dose of misoprostol while none of the patients in control group experienced significant contraction during the same period. Over half $(50.6 \%)$ of controls needed oxytocin for induction as opposed to none in the study group. The need for oxytocin during labour in study cases were significantly less $(37.2 \%)$ than that in controls $(80.5 \%) \quad(p=0.024)$. The incidence of failed induction was even less in cases $(11.6 \%)$ than that in controls $(44.2 \%)(p=0.001)$ (Table II).

\begin{tabular}{|lrrr|}
\hline \multicolumn{4}{|c}{ TABLE I. Demographic characteristics between two groups } \\
$\begin{array}{l}\text { Group } \\
\text { Demographic characteristics }\end{array}$ & $\begin{array}{c}\text { Study } \\
(\mathrm{n}=43)\end{array}$ & $\begin{array}{c}\text { Control } \\
(\mathrm{n}=43)\end{array}$ & p-value \\
\hline Maternal age (years)* & & & \\
$<25$ & $11(25.6)$ & $19(44.2)$ & \\
$25-30$ & $19(44.2)$ & $19(44.2)$ & \\
$\geq 30$ & $13(30.2)$ & $5(11.6)$ & \\
Mean \pm SD \# & $26.9 \pm 3.4$ & $25.2 \pm 3.1$ & 0.058 \\
Para* & & & \\
Primipara & $30(69.8)$ & $31(72.1)$ & 0.812 \\
Multipara & $13(30.2)$ & $12(27.9)$ & \\
H/O past abortion* & $8(18.6)$ & $5(11.6)$ & 0.366 \\
\hline
\end{tabular}

Figures in the parentheses indicate corresponding \%;

* Chi-squared Test $\left(\chi^{2}\right)$ was done to analyze the data.

\# Data were analyzed using Unpaired t-Test and were presented as mean \pm SD.

Table III shows that $4.7 \%$ of patients in study group developed uterine hyperstimulation, $2.3 \%$ uterine tachysystole and another $2.3 \%$ nausea/ vomiting while none of patients in the control group developed the same complications. One $(2.3 \%)$ patient in study group experienced chorioamnionitis and $9.3 \%$ exhibited group-B Streptococci in high vaginal swab culture.

\begin{tabular}{|c|c|c|c|}
\hline \multirow[b]{2}{*}{ Induction related variables } & \multicolumn{2}{|c|}{ Group } & \multirow[b]{2}{*}{ p-value } \\
\hline & $\begin{array}{l}\text { Study } \\
(n=43)\end{array}$ & $\begin{array}{l}\text { Control } \\
(n=43)\end{array}$ & \\
\hline $\begin{array}{l}\text { Interval from rupture of membrane } \\
\text { to uterine contractions }{ }^{\#}\end{array}$ & $8.8 \pm 3.4$ & $15.0 \pm 4.7$ & $<0.001$ \\
\hline \multicolumn{4}{|c|}{ Interval between rupture of membrane \& delivery* } \\
\hline$\leq 24 \mathrm{hrs}$ & $41(94.3)$ & 28(64.4) & \multirow{3}{*}{$<0.001$} \\
\hline$>24 \mathrm{hrs}$ & $2(5.7)$ & 15(35.6) & \\
\hline Mean \pm SD & $11.5 \pm 3.5$ & $18.7 \pm 5.7$ & \\
\hline \multicolumn{4}{|l|}{ Oxytocin needed* } \\
\hline For induction & $0(0.0)$ & $22(50.6)$ & 0.134 \\
\hline During labour & $16(37.2)$ & $35(80.5)$ & 0.024 \\
\hline Induction failed ${ }^{*}$ & $5(11.6)$ & $19(44.2)$ & 0.001 \\
\hline
\end{tabular}

Figures in the parentheses indicate corresponding \%; *Chi-squared Test $\left(\chi^{2}\right)$ was done to analyze the data. \#Data were analyzed using Unpaired t-Test and were presented as mean \pm SD. 
In contrast, $18.6 \%$ of the controls developed chorioamnionitis and $14 \%$ showed the presence of group-B Streptococci in high vaginal swab. In terms of mode of delivery, normal vaginal delivery (NVD) occurred in $88.4 \%$ of the study group as compared to $53.5 \%$ in controls $(p<0.001)$. There was no significant difference between the groups in terms of foetal distress $(p=0.747)$ and neonatal sepsis $(p=0.121)$. Over half of the patients in the both groups had a history of less than 4 vaginal examinations during labour.

\begin{tabular}{|c|c|c|c|}
\hline \multirow[b]{2}{*}{ Induction related variables } & \multicolumn{2}{|c|}{ Group } & \multirow[b]{2}{*}{ p-value } \\
\hline & $\begin{array}{l}\text { Case } \\
(n=43)\end{array}$ & $\begin{array}{l}\text { Control } \\
(n=43)\end{array}$ & \\
\hline Uterine hyperstimulation ${ }^{* *}$ & $2(4.7)$ & $0(0.0)$ & 0.247 \\
\hline Uterine tachysystole ${ }^{* *}$ & $1(2.3)$ & $0(0.0)$ & 0.500 \\
\hline Nausea/vomiting** & $1(2.3)$ & $0(0.0)$ & 0.500 \\
\hline Chorioamnionitis** & $1(2.3)$ & $8(18.6)$ & 0.015 \\
\hline $\begin{array}{l}\text { Presence of Group-B Streptococci in } \\
\text { vaginal culture** }\end{array}$ & $4(9.3)$ & $6(14.0)$ & 0.501 \\
\hline \multicolumn{4}{|l|}{ Mode of delivery* } \\
\hline NVD & $38(88.4)$ & $23(53.5)$ & \multirow{2}{*}{$<0.001$} \\
\hline Caesarean section & $5(11.6)$ & $20(46.5)$ & \\
\hline
\end{tabular}

Figures in the parentheses indicate corresponding \%;

* Chi-squared Test $\left(\chi^{2}\right)$ was done to analyzed the data.

**Fisher's Exact Test was done to analyzed the data.

There was no significant difference between the groups with respect to Apgar score at 1 minute of birth, neonatal sepsis and foetal distress $(p=0.063$, $p=0.121$ and $p=0.747$ respectively) (Table IV).

\begin{tabular}{|c|c|c|c|}
\hline \multirow[b]{2}{*}{ Outcome } & \multicolumn{2}{|c|}{ Group } & \multirow[b]{2}{*}{ p-value } \\
\hline & $\begin{array}{c}\text { Case } \\
(n=43)\end{array}$ & $\begin{array}{l}\text { Control } \\
(n=43)\end{array}$ & \\
\hline Foetal distress* & $5(11.6)$ & $6(14.0)$ & 0.747 \\
\hline Neonatal sepsis ${ }^{* *}$ & $0(0.0)$ & $3(6.9)$ & 0.121 \\
\hline Apgar score $<7$ at 1 minute* & $5(11.6)$ & $5(11.6)$ & 0.063 \\
\hline
\end{tabular}

Figures in the parentheses indicate corresponding \%;

* Chi-squared Test $\left(\chi^{2}\right)$ was done to analyzed the data.

**Fisher's Exact Test was done to analyzed the data.

\section{DISCUSSION}

In the present study case and control groups were almost identical in terms of maternal age, parity and history of past abortion. Shetty et al. ${ }^{15}$ conducted a similar study, where there were no differences in maternal age between women with active and conservative management of PROM (29.2 vs. 29.2 years respectively). In our study two-thirds of the women in both active and conservative management groups were primipara. Majority $(94.3 \%)$ of the patients in active management group and $64.4 \%$ in conservative group required 24 or $<24$ hours to deliver their babies. The mean interval between ROM and uterine contraction and that between ROM and delivery were much less in the former group than those in later group $(p<0.001$ and $p<0.001$ respectively). About $63 \%$ of active group exhibited significant uterine contractions after $1^{\text {st }}$ dose, $23.3 \%$ after $2^{\text {nd }}$ dose, $9.3 \%$ after $3^{\text {rd }}$ dose and $4.7 \%$ after $4^{\text {th }}$ dose of misoprostol. Twenty two $(50.6 \%)$ of conservative group needed oxytocin for induction as opposed to none of the active group. The need for oxytocin during labour in active group were significantly less (37.2\%) than that in conservative group $(80.5 \%)(p=$ $0.024)$. The incidence of failed induction was staggeringly higher in conservative group (44.2\%) than that in active group $(11.6 \%)(p=0.001)$. This is similar to the observation of Ayaz et al ${ }^{16}$ who reported $67 \%$ of the patients with significant uterine contractions after a single dose of misoprostol, while $16 \%, 10 \%$ and $7 \%$ had contractions after 2 nd, 3 rd and 4 th doses respectively.

All study subjects in the active group showed significant uterine contractions within 24 hours of PROM compared to $69 \%$ in conservative group. The mean interval between PROM and the onset of significant uterine contractions was 8.8 hours in active group and 15.0 hours in conservative group $(p<0.001)$. Incidence of failed induction active in group was $11.6 \%$ and in conservative group $44.2 \%(p=0.001)$. About $5 \%$ of patients in active group developed uterine hyperstimulation, $2.3 \%$ uterine tachysystole and another $2.3 \%$ nausea/ vomiting while none of the patients in conservative group developed the same complications. A significant proportion of women in the conservative group (18.6\%) developed chorioamnionitis and $14 \%$ showed the presence of group-E Streptococci in high vaginal swab. In contrast, only $1(2.3 \%)$ patient in active group 
experienced chorioamnionitis and $9.3 \%$ exhibited group-E Streptococci in high vaginal swab culture. In terms of mode of delivery, the active group had a significantly higher rate of normal vaginal delivery $(88.5 \%)$ with fewer caesarean section compared to the conservative group (53.5\%) $(p<0.001)$. Chorioamnionitis is a potentially serious complication resulting from conservative treatment because of the increased interval between PROM and delivery. Five $(11.6 \%)$ of the active group had foetal distress compared to $6(14 \%)$ of conservative group ( $p=0.747)$. About $5 \%$ of patients in conservative group had neonatal sepsis while none of patients in active group had the same complication $(p=0.121)$. There was no significant differences between the groups with respect to Apgar score at 1 minute of birth and number of vaginal digital examinations ( $p=0.063$ and 0.569 respectively). Almost similar findings were reported by Ayaz et al. ${ }^{17}$ They reported that only three $(7 \%)$ women in study group developed complications (two cases of uterine hyperstimulation and one of uterine tachysystole), while six (14\%) patients in conservative group experienced complications (five cases of chorioamnionitis and one nausea and vomiting). Overall, the foetal/neonatal complication rate in the two groups was equal (5\%). Seven percent of patients had Apgar score $<7$ at 1 minute of birth in the active group compared to $10 \%$ in the conservative group. Gibbs et al ${ }^{18}$ however, found a high rate of chorioamnionitis.

\section{CONCLUSION}

From the findings of study, it can be concluded that management of premature rupture of membrane with unfavourable cervix using vaginal misoprostol increases the rate of vaginal delivery thereby reducing the risk of caesarean section, while conservative management usually fails to induce spontaneous onset of labour and thus vaginal delivery.

\section{REFERENCES}

1. Gumm GC, Mishell DR Jr., Morton DG. Premature rupture of foetal membrane: A review. Am J Obstet \& Gynaecol 1970;106:469-83.

2. Alexaneder JM, Cox SM. Clinical course of premature rupture of the membranes. Semin perinatal 1996;20(5):369-74.
3. Johnson JW, Daikoku NH, Niebyl JR, Johnson TR Jr, Khouzami VA, Witter FR. Premature rupture of the membranes and prolonged latency. Obstct Gynaecol 1981;57(5):547-56.

4. Hannah ME, Ohlsson A, Farine D. Induction of labor compared with expectant management for prelabor rupture of the membrane at term. $N$ Eng $J$ Med 1996;16:005-10.

5. Shubeck F, Benson RC, Clark WW Jr., Berendes H, Weiss W, Dutschberger J. Foetal hazards after rupture of the membranes: A report from the collaborative project. Obstet Gynaecol 1966;28(1):22-31.

6. Shetty A, Stewart K, Stewart G, Rice P, Danielian P, Templeton A. Active management of term prelabour rupture of membranes with oral misoprostol. BJOG 2002;109:354-58.

7. Goldberg AB, Greenberg MB, Barney PD. Misoprostol and pregnancy. N Eng J Med 2001;344:38-47.

8. Hofmeyr GJ, Alfirevic Z, Matonhodze B, Brocklehurst P, Campbell E, Nikodem VC. Titrated oral misoprostol solution for induction of labour a multi- centre, randomized trial. BJOG 2001;108:952-9.

9. Mbele AM, Makin TD, Pattinson RC. Can the outcome of induction of labour with oral misoprostol be predicted? $S$ Afi Med J 2007;97:289-92.

10. Zeiman M, Fong SK, Benowitz NL, Banskter D, Darney PD. Absorption benefits of misoprostol with oral or vaginal administration. Obstet Gynecol 1997;90:88-92.

11. Winclrim R, Bennett K, Mundie W, Young DC. Oral administration of misoprostol for labor induction: a randomized controlled trial. Obstet Gynecol 1991;89:392-1.

12. Butt KD, Bennett K, Crane JMG, Hutchens D, Young DC. Randomized comparison of oral misoprostol and oxytocin for labor induction in term prelabor membrane rupture. Obstet Gynccol 1999;94:994-9.

13. Alfircvrc Z. Oral misoprostol for induction of labor (Cochrane review). In: The Cochrane Library, Issue 4. Oxford: Update Software, 2002.

14. Natale R, Miline JK, Campbell MK, Potts PG, Webster K, Halincla E. Management of premature rupture of membranes at term: randomized trial. Am J Obstet Gynecol 1994;171:936-9.

15. Shetty A, Stewart K, Stewart G, Rice P, Danielian P, Templeton A. Active management of term prelabour rupture of membranes with oral misoprostol. BJOG: an International Journal of Obstetrics and Gynaecology 2002;109:1354-8.

16. American College of Obstetricians and Gynecologists. Response to Searle's drug warning on misoprostol. In: ACOG Committee Opinion No. 248. Washington: American College of Obstetricians and Gynecologists, 2002.

17. Ayaz A, Saeed S, Farooq MU, Ahmed F, Bahoo LA, Ahmed I. Pre-labor Rupture of Membrane at Term in Patients with an Unfavorable Cervix: Active versus Conservative Management. Taiwan Obstet Gynecol 2008;47(2):192-6.

18. Gibbs RS, Blanco TD, St Clair PJ, Castaneda YS. Quantitative bacteriology of amniotic fluid from women with clinical intra-amniotic infection at term. J Infect Dis 1982;145:1-8. 